\title{
THE ELECTROCHEMICAL INFLUENCE AND OXYCIN EXCHANGE PROPERTIES OF MIXED CONDUCTING ELECTRODE MATERIALS ON SOLID OXIDE ELECTROLYTES
}

\author{
I.C. VINKE, K. SESHAN, B.A. BOUKAMP, K.J. de VRIES and A.J. BURGGRAAF \\ Laboratory of Inorganic Chemistry, Materials Science and Catalysis, Faculty of Chemical Technology, University of Twente, \\ P.O. Box $21 \%, 7500$ AE Enschede, The Netherlands
}

Received 17 August 1987; in revised version 7 March 1988

\begin{abstract}
Electrolyte electrode materials combinations of $\mathrm{Er}_{2} \mathrm{O}_{3}$ stabilized $\mathrm{Bi}_{2} \mathrm{O}_{3}$ and mixed i.e. both electronic and ionic conducting materials are investigated in order to lower electrode polarization losses and operating temperatures of electrochemical sensors, pumps and SOFC reactors made of them. ${ }^{18} \mathrm{O}$ exchange rates are correl: ted with exchange current densities.
\end{abstract}

\section{Introduction}

Solid electrolytes based on oxygen ion conductors find extensive applications as devices for oxygen sensor, oxygen pumps, solid oxide fuel cells and electrocatalytic reactors. When using ceramic ionic conductors for applications, frequent attempts are made to improve the performance of the electrochemical system by applving mixed conductors as thin top layers instead of the conventional inert noble metal electrodes [1-4]. A development of a new oxygen ion conductor will therefore be accompanied by research for suitable electrode materials. It has been argued that materials most suited for electrode applications are to be found among the mixed conducting oxides $[4,5]$. One of the mixed conducting oxides studied is terbia-stabilized $\delta$-bismuth(III) oxide as it follows from earlier research that the $\mathrm{Bi}_{2} \mathrm{O}_{3}$ based electrolytes most probably have good oxygen exchange properties. This material was also chosen for its compatibility with the electrolyte used i.e. $\mathrm{Bi}_{2} \mathrm{O}_{3}$ stabilized with $25 \% \mathrm{Er}_{2} \mathrm{O}_{3}$ (BE25). Probably in this way interfacial polarization effects between the mixed conducting oxide and the solid electrolyte can be minimized [6]. In order to study the performance of this system, current against overvoltage measurements were carried out. An attempt has been made to check the influence of the electrode electrolyte interfac $z$ on the performance of the electrode.

\section{Experimental}

The measurements were made using a disk shaped BE 25 electrolyte samples with a diameter of $12 \mathrm{~mm}$ and with a working electrode of $400 \mathrm{~nm}$ thickness sputtered on one side of the electrolyte. $\mathrm{Bi}_{2} \mathrm{O}_{3}$ stabilized with $50 \% \mathrm{~Tb}_{2} \mathrm{O}_{3}$ (BT50) was used as electrode. The electrode electrolyte combinations were annealed at $1023 \mathrm{~K}$. The samples were placed in a three electrode cell with gold annular working and counter electrodes of $10 \mathrm{~mm}$ outer diameter and 6 $\mathrm{mm}$ inner diameter making contact on either side of the electrolyte sample. A point shaped reference electrode was placed in the center of the working electrode. This configuration was chosen for it $\mathrm{min}$ imizes the potential drop between the reference and the working electrode [7].

To ensure good contact between the contacts of the cell and the sample, porous gold layers of 300-400 nm of the same shape and size as the contacts of the cell were sputtered onto the electrolyte/electrode combination. To study the influence of the electrode electrolyte interface, a full circular layer of BT50 or an annular shaped BT50 layer of $10 \mathrm{~mm}$ outer and $5 \mathrm{~mm}$ inner diameter were suputiered onto BE25 samples, Using these two electrode structures for current overvoltage $(I-V)$ measurements a difference in the virtual position of the reference electrode is generated. In case of the ring shaped BT50 electrode, the polarization due to the electrolyte elec- 
trode interface is added to the potential difference between the vorking and the reference electrode observed for the full BT50 layer. This allows for a study of the effect. These electrode arrangements minimize electrode norphology effects as it is observed that sputtered thin layers may perform differently from bulk material [4]. As a reference system BE25 with an annular porous gold electrode was chosen.

The $I-V$ measurements were conducted using a Solartron 1286 potentiostat generating a stepped voltage scan. Data were transferred to an Apple IIc micro computer and analyzed in terms of a ButlerVolmer relation using a nor linear least square (NLLS) fit $I-V$ data analysis package running on any Apple II micro computer system [ 7]. The oxygen exchange coefficients obtained from the analysis are compared with the results of ${ }^{18} \mathrm{O}$ exchange experiments [8].

\section{Results and discussion}

A typical example of the $I-V$ results is presented in fig. 1. This :raph clearly shows high polarization in the cathodic branch and therefore meets the requirements of the computer analysis r: Jgram mentioned above [7]. These analyses generate values for the exclisuge current densities $\left(i_{0}\right)$, the anodic and

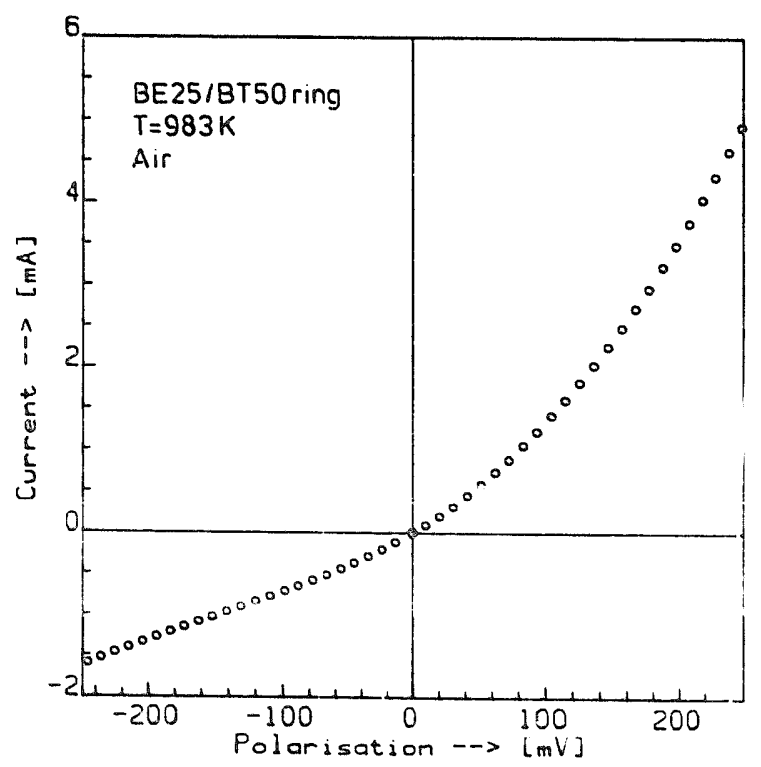

Fig. 1. Three electrode current voltage measurement performed on a BE25 sample with a BT50 ring electrode at $983 \mathrm{~K}$ in sir. cathodic exchange coefficients $\left(\alpha_{\mathrm{a}}, \alpha_{\mathrm{c}}\right)$ and the ohmic resistance $\left(R_{\mathrm{u}}\right)$ between the reference and the working electrode.

Fig. 2 gives a comparison between the electrochemically established exchange coefficients and the corresponding exchange values from the ${ }^{18} \mathrm{O}$ data for BE25 in air $\left(P_{\mathrm{O}_{2}}=0.21\right)$ at different temperatures. A detailed study will be published elsewhere [8]. The values are in good agreement indicating that the parameters obtained by the NLLS-fit procedure are reliable.

Comparing the $i_{0}$ values for the BE25 electrolyte BT50 electrode combination with BE25 having gold electrodes shows a small decrease in activity for the samples with the BT50 electrode (fig. 2). As can be seen in fig. 2 no difference in activation enthalpy exists between the three samples. From ${ }^{18} \mathrm{O}$ experiments the exchange rate for BT-materials is known to be higher by a facor of 2 to 4 than the exchange rate for BE25 [9]. Moreover, the activation enthalpy for the exchange process on BT-materials is different from the activation enthalpy on BT25 [9]. Our results suggest therefore that the BT50 layer has reacted with the top layer of the BE25 electrolyte to form a solid solution with pioperties comparable to BE25.

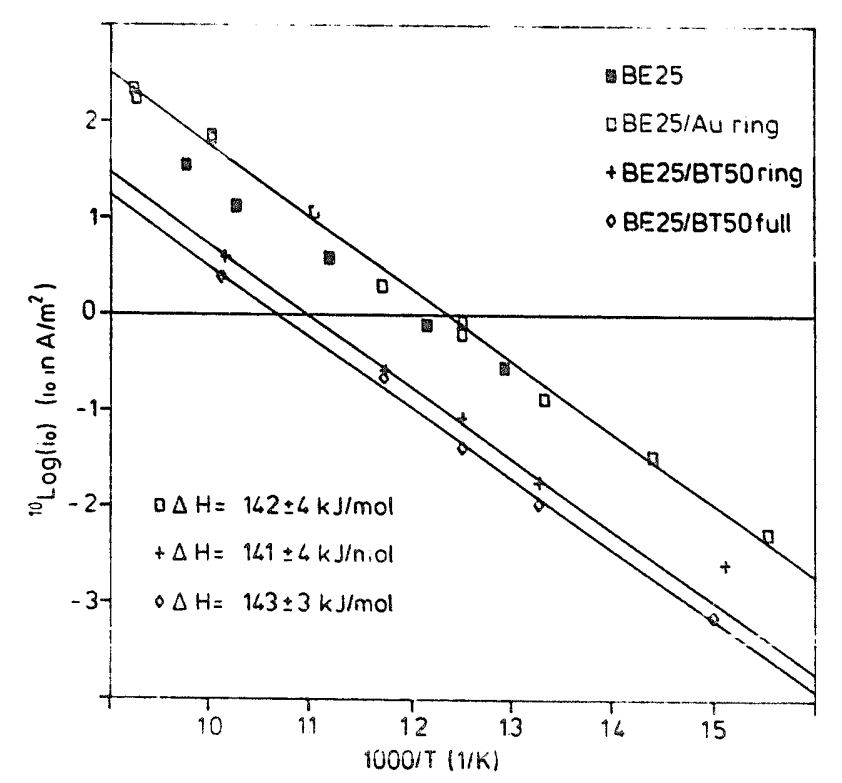

Fig. 2. Oxygen exchange current densities calculated from ${ }^{18} \mathrm{O}$ exchange experiments on BE25 (월) and electrochemical measurements on BE25 with a gold ring elsctrode ( $\square$ ), a BT50 ring electrode $(t)$ and a BT50 full electrode $(\diamond)$, as a function of temperature under a $P_{0 .}=0.21 \mathrm{~atm}$. 
Although the exchange process seems to be the same on both materials this does not hold for the driven oxygen uptaken reaction. From fig. 3 it can be concluded that the cathodic process is not influenced by the surface modification. The curve for $\alpha_{\mathrm{a}}$ suggests that existence of a maximum around a temperature of about $800 \mathrm{~K}$ (see further [9]). This implies that the anodic exchange coefficient is lowered because of the BT50 layer. As the sum of the exchange coefficients on BT50 is close to 2 over a wide temperature range, the theory of Bockris and Reddy [10] suggests that on a thin BT50 electrode layer the diffusion processes play a less important role than on a BE25 sample with gold electrodes [9].

To study the influence of the electrode electrolyte interface on the oxygen transport process a close look at the values of the resistance between the reference and the working electrode is necessanj. As stated tefore, the difference in this parameier is attributable to this interface. Fig. 4 shows only a slight difference between the $R_{\mathrm{u}}$ of BE25 with a gold electrode and BE25 with a ring electrode of BT50. Both lines also show a tendency to curving above a temperature of $800 \mathrm{~K}$ which is typical of BE25 [9]. The activation enthalpy of $145 \mathrm{~kJ} / \mathrm{mol}$ with the gold electrode and $156 \mathrm{~kJ} / \mathrm{mol}$ with the $\mathrm{BT} 50$ ring electrode on $\mathrm{BE} 25$, in the linear region below $800 \mathrm{~K}$, do not match with

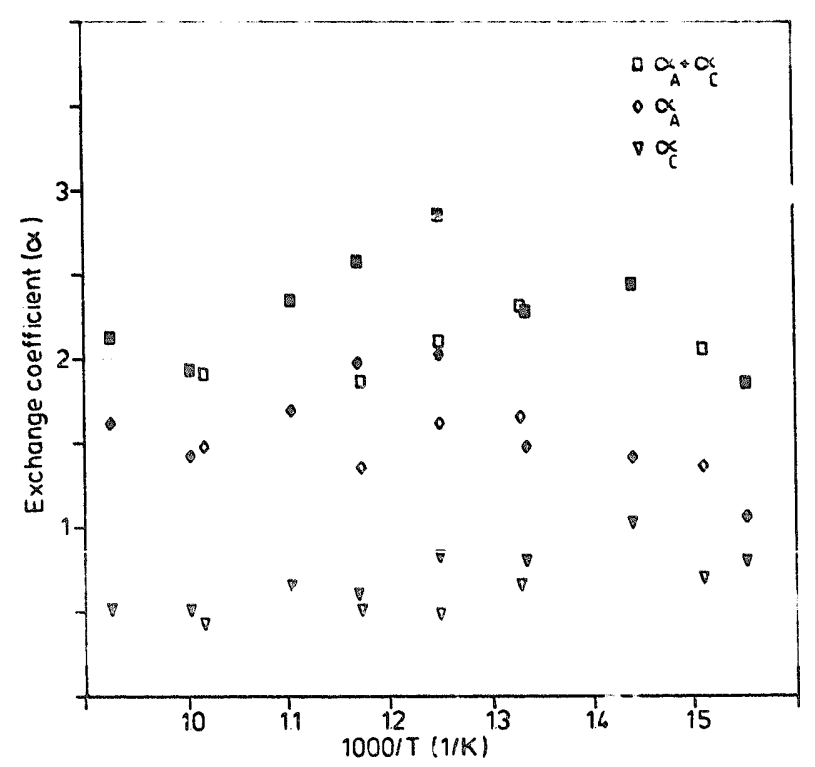

Fig. 3. Oxygen exchange coefficients for BE25 with a gold ring electrode (closed symbols) and a BT50 full electrode (open symbols) as a functior of temperature in air.

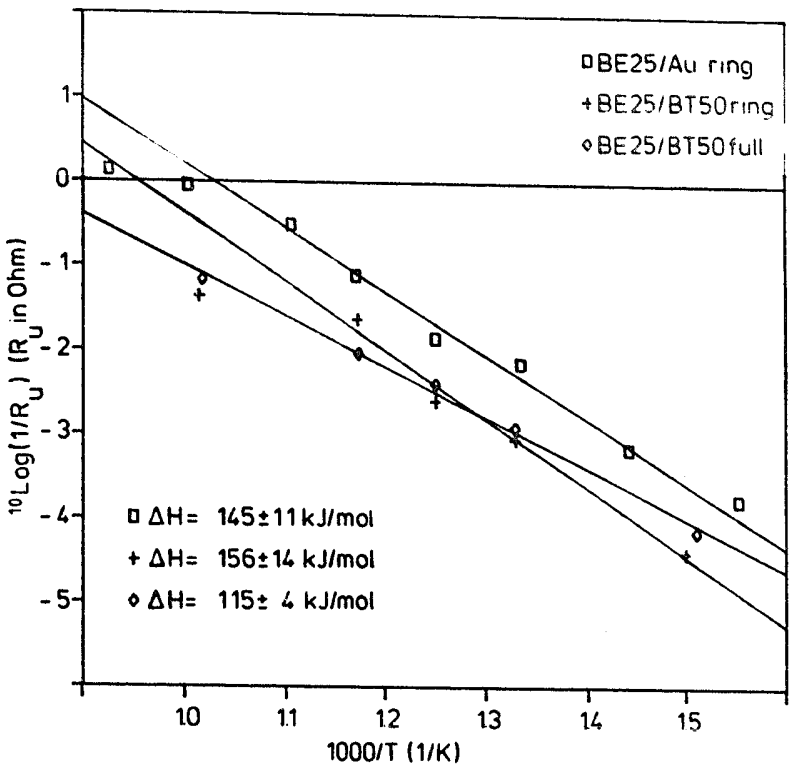

Fig. 4. Resistance between the reference and working electrode for BE25 with a gold ring electrode ( $\square$ ), a BT50 ring electrode $(+)$ and a BT50 full electrode $(\diamond)$ as a function of temperature in air.

the activation enthalpy for the bulk conductivity of BE25 (117 kJ/mol) [9].

Fig. 4 also presents the Arrhenius plot of the conductivity for the two different BT50 electrode configurations. A clear difference can be observed between the two configurations. The electrode consisting of a full layer of BT50 shows a lower activation enthalpy of $115 \mathrm{~kJ} / \mathrm{mol}$ ard shows no tendency to curve. This activation enthalpy is also higher than the activation enthalpies mentioned in literature for BT-systems [11,12]. The absolute $\boldsymbol{R}_{\mathrm{u}}$ values of the materials BE25 and BT50 in the two investigated electrode configurations are however comparable.

The result of the comparison of the two different electrode configurations implies that the main component in the $R_{\mathrm{u}}$ will bo attributable to the bulk resistance of the material between the working and the reference electrode and that the poiarization across the electrode electrolyte interface in this case is of minor importance. This may be caused by the apparent reaction at the annealing temperature of the thin electrode layer with the electrolyte modifying the interface. This results in a layer with an increased rare earth concentration lowering the oxygen conductivity $\llbracket 13 \rrbracket$. The same process lowers the elec- 
tronic conductivity of the sample by lowering the terbium concentration [14]. This will have to be checked by frequency dispersion measurements and I-V measurements on thick BT50 electrode layers. Furthermore attempts will be made to check the extent of mixing of the electrolyte and electrode by concentration depth profiling.

\section{Conclusions}

The BT50 electrode layer seems to have reacted with the electrolyte support forming a top layer with less favourable properties for the oxygen uptake reaction.

The electrode electrolyte interface has probably been spread over a larger region and has little influence on the electrode polarization.

\section{Acknowledgement}

This investigation was supported by the Dutch Foundation for Chemical Research (SON) with the financial aid from the Dutch Organization for the Advancement of Pure Research (ZWO).

\section{References}

[1] M.P. van Dijk, J.H.H. ter Maat, G. Roelofs, H. Bosch, G.M.H. van de Velde, P.J. Gellings and A.J. Burggraaf, Mater. Res. Bull. 19 (1984) 1149.

[2] A.J. Burggraaf, D. Scholten and K.J. de Vries, submitted for publication.

[3] O. Yamamoto, Y. Takeda, R. Kanno and M. Noda, Solid State Ionics 22 (1987) 241.

[4] M.P. van Dijk, K.J. de Vries and A.J. Burggraaf, Solid State Ionics $\because$ (1986) 73.

[5] M.P. van Dijk, Ph.D. Thesis (University of Twente, Department of Chemical Technology, Enschede, The Netherlands, 1985) p.77.

[6] S.P.S. Badwal and F.F. Ciachi, J. Appl. Electrochem. 16 (1986) 28.

[7] B.A. Boukamp, I.C. Vinke, K. Seshan, K.J. de Vries and A.J. Burggraaf, Solid State Ionics 28-30 (1988) 1187.

[8] B.A. Boukamp, I.C. Vinke, K.J. de Vries and A.J. Burggraaf, in: Proc. 11th Intern. Symp. Reactivity of Solids (1988), submitted for publication.

[9] I.C. Vinke, K. Seshan, B.A. Boukamp, K.J. de Vries and A.J. Burggraaf, Electrochemical Properties of Ceramic Bismuth(III)Erbium Oxide Solid Solutions, to be published.

[10] J.O.M. Bockris and A.K.H. Ready, Modern electrochemistry, (Plenum Press, New York, 1970), Chap. 9.1.

[11] T. Esaka and H. Iwahara, J. Appl. Electrochem. 15 (1985) 447.

[12] P. Shuk, S. Jacobs and H.H. Nobius, Z. Anorg. Allg. Chem. $524(1985) 144$.

[13] M.J. Verkerk and A.J. Burggraaf, Solid State lonics 3/4 (1981) 463 .

[14] B.A. Boukamp, M.P. van Dijk, K.J. de Vries and A.J. Burggraaf, Adv. Ceramics 23 (1987) 447. 